\title{
XLV. Analysis of arsenical nickel, and the arseniate of nickel of Allemont (Department of the Isere)
}

\section{Berthier}

To cite this article: M. Berthier (1820) XLV. Analysis of arsenical nickel, and the arseniate of nickel of Allemont (Department of the Isere) , Philosophical Magazine Series 1, 56:270, 295-299, DOI: $10.1080 / 14786442008652408$

To link to this article: http://dx.doi.org/10.1080/14786442008652408

里 Published online: 23 Jul 2009.

Submit your article to this journal $₫$

Џll Article views: 3

Q View related articles ๘ 
the space will allow of? They should be calculated to bear the greatest possible load, with safety. My experiments furnish the necessary data as far as regards the strength of the stone. They also show which stone is best adapted for the purpose. The Dundee stone is decidedly the strongest of the specimens I have tried.

Oct. 17,1820

I an, sir, yours, \&c.

2, Grove Terrace, Lisson Grove.

XLV. Analysis of Arsenical Nickel, and the Arseniate of Nickel of Allemont (Department of the Isere). By M.BerTHIER*.

$\mathbf{T}$ $\mathrm{T}_{\mathrm{H}} \mathrm{E}$ arsenical nickel of Allemont has not hitherto been completely analysed. Its colour is reddish brown, approaching that of copper, but paler; it has a metallic lustre both in pieces and in powder ; its fracture even, or covered with small asperities, and a little shining; it soon tarnishes in the alr ; it is brittle, and easily reduced to powder:- specific gravity $7 \cdot 29$. It emits a garlic smell when struck with steel; before the blow-pipe it gives a dense arsenical smoke; melts readily a little above a red heat. Heated for an hour at $150^{\circ}$ of Wedgwood, in a crucible lined with charcoal, it loses only about 0.12 to 0.15 of its weight, and does not change its appearance. 'This loss appears to be almost entirely arsenic.

This mineral consists principally of arsenieuret of nickel, but contains also a small quantity of arsenieuret of cobalt and sulphuret of antimony. It was analysed in the manner following:

To the mineral was added nitric aeid at intervals; and it was boiler during two days, which dissolved the whole. The arsenic and sulphur were acidified, and the nickel, cobalt and antimony oxidated. Water being added to the solution, a white powder fell down, weighing when dry 0.2.76 parts, which was proved to consist almost entirely of arseniate of antimony, by the following experiments : It was first heated in a silver crucible, with four times its weight of caustic potash; and then treated with boiling water, which dissolved all but a small residue of oxide of nickel, weighing $0 \cdot 008$, arising from a small portion of arseniate of nickel which had fallen down along with the arseniate of antimony. The above-mentioned solution in boiling water was then boiled with vitric acid, which produced a white sediment, composed of oxide of antimony and arsenic acid, weighing 0.16 parts: Its component parts were separated by solution in muriatic acid, slow evaporation to dryness, and subsequent addition of water, which caused a copious deposit of in-

* From the Journ. des Mines, iv. 467. 
soluble oxide of antimony. A second evaporation to dryness of the soluble part, and re-solution in water, gave a further small deposit of oxide of antimony, after which the solution was no longer troubled by sulphuretted hydrogen. The whole of the oxide of antimony weighed after calcination 0.11 parts, which, subtracted from the weight of the arseniate of antimony, leaves 0.158 for the arsenic acid.

The nitric solution, which had parted with the arseniate of antimony by dilution with water, was then decomposed by subcarbonate of soda added in slight excess; a pale apple-green precipitate fell down, weighing after drying $1 \cdot 030$ parts ; and consisted of arseniated nickel with a smail proportion of arseniated cobalt. As a proof that this solution had parted with all its arseniate of antimony, a portion of the apple-green precipitate was calcined, re-dissolved in nitric acid, evaporated slowly to dryness, and again dissolved in water, without leaving any residue; which would have been the case had any antimony been present.

The 1.030 parts of arseniate of nickel were decomposed in a silver crucible by potash ; and yielded nearly equal parts of oxide of nickel and arsenic acid. To separate from the latter the minute quantity of oxide of cobait, it was dissolved in muriatic acid, precipitated by carbonate of soda, changed to an oxalate by digestion with oxalic acid, and then dissolved in ammonia, according to the process described by $M$. Laugier in the $9 \mathrm{th}$ volume of Annales de Chimie el de Physique. In this way about 0.002 of oxide of cobalt was detected.

As the liquid whence the arseniate of nickel had been precipitated by the carbonate of soda might retain some arsenic acid, a known weight of peroxide of iron dissolved in muriatic acid was dropped in, and again precipitated by carbo. nate of soda, and dried. This precipitate weighed 0.054 more than the peroxide of iron first used, which increase was therefore arsenic acid. Lastly, all the clear solution was supersaturated with nitric acid, and treated with nitrate of barytes, which threw down 0.14 parts of sulphate of barytes, equal to 002 of sulphur.

The above analysis therefore yielded the following products:

\begin{tabular}{|c|c|c|c|c|}
\hline Protoxide of nickel & & & & 0.51 \\
\hline Protoxide of cobalt & & & & \\
\hline Arsenic acid & - & . & • & $0 \cdot 7$ \\
\hline Sulphuric acid $\quad$. & . & .. & $\cdot$ & 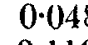 \\
\hline Oxide of antimony & .. & • &. & 0 . \\
\hline
\end{tabular}

with a trace of oxide of iron and manganese. 
But as the process of analysis oxidates the several bases which in the mineral in its natural state exist free from oxygen, the component parts of this ore must be stated as follows:

$\begin{array}{llll}\text { Nickel .. } & 0.3994 & \text { or Arseniuret of nickel } & 0.8855 \\ \text { Cobalt . } & 0.0016 & \text { Arseniuret of cobalt } & 00035 \\ \text { Arsenic .. } & 0.4880 & \text { Sulphuret of antimony } & 0 \cdot 1000 \\ \text { Antimony } & 0.0800 & & \\ \text { Sulphur } & 0.0200 & & 0.9890 \\ & 0.9890 & \end{array}$

The pure arseniuret of nickel therefore contains 0.451 per cent. of nickel, and 0.549 of arsenic, numbers differing but little from -44 and $\cdot 56$, which are given by calculation.

The arseniate of nickel, which is always found at Allemont adhering to arsenical nickel, appears to be derived from the spontaneous decomposition of the latter. It is sometimes compact, and of a very fine apple-green, sometimes friable and greenish white. The latter variety was analysed by fusion in a silver crucible with one and a half its weight of potash, and assayed for cobalt by the process of M. Laugier mentioned above. It gave the following component parts :

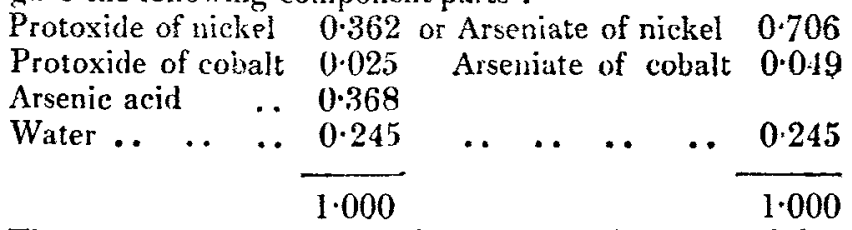

The pure arseniate of nickel therefore will consist of 0.512 per cent. of oxide of nickel, and 0.438 of arsenic arid, which is nearly the composition of the artificial sub-arseniate, that would be formed by three atoms of oxide and two atoms of acil, or, exactly, of 0.496 of oxide of nickel and 0.504 of arsenic acid.

\section{Preparation of Nickel, and Examination of some of its Salts.}

The ore of Allemont, after being roasted till all arsenical vapour ceased, was dissolved in nitro-muriatic acid, and evaporated to dryness at a gentle heat. On adding water to the residue, there remained much arseniate of antimony: the solution was then decomposed by common subearbonate of soda, till the white precipitate of arseniate of antimony began to be coloured, and then filtered. The liquor contained all the nickel, with a little cobalt and arsenic acid. To separate the latter, a solution of muriated peroxide of iron was added, followed by subearbonate of soda, till the precipitate began to show either a green or a rosecolour, and the liquor was again filtered. The subcarbonate of

Vol. 56. No. 270. Oct.1820. P P soda 
soda throws down at first the arseniate of iron, and then any simple peroxide that may remain, if more muriate of iron was added than was necessary to afford sufficient peroxide of iron to saturate the arsenic acid. The arseniate of iron is yellowish white, the simple peroxide brown-red, showing that no arsenie acid remains in the solution, if the ferrugineous precipitate, after being yellowish white, appears red in the last portions ; and indeed if this does not happen at first, moze of the muriate of iron should be added, till the brown-red precipitate shows itself. All the arsenic acid and oxide of iron being thus got rid of, nothing but nichel and cobalt remains in the solution, which must then be separated. The process of M. Laugier answers this purpose completely; but, as M. Tupdti observes, where it is only desired to procure a quantity of pure oxide of vickel, without regard to accuracy of analysis, it is a much cheaper and simpler method to add an alkaline subcarbonate to the solution of the two metals; which first throws down the pure rose-coloured oxide of cobalt, then a mixture of the two metals, and lastly pure oxide of nickel. When only the latter is left in the solution, it is to be boiled with an alkaline subcarbonate, and the precipitated oxide well washed.

\section{Arseniate of Nickel.}

To prepare this salt, 1.96 gramme of oxile of nickel was dissolved in muriatic acid, thrce grammes of arsenic aeid in water were added, and then preeipitated by a subcarbonate of alkali, and the whole was filtered and the liquor boiled, to throw down the small quantity of arseniate held in solution by the carbonic acid. The arseniate of nickel thus obtained, weighed after calcination $3.91 \mathrm{gr}$. being exactly douhle the weight of the oxide of nickel. To recover the remainder of the arsenic acid, one gramme of peroxide of iron in muriatic acid was poured in, and the arseniate of iron was precipitated by an alkali; it weighed $\mathrm{l} .97 \mathrm{gr}$. of which consequently $0.97 \mathrm{gr}$. was arsenic acid. A loss of $0.08 \mathrm{gr}$. appears in this operation : nevertheless it may be concluded that arseniate of nickel entains nearly equal parts of acid and oxide-a result confirmed in various ways.

From the known composition of protoxide of nickel and of arsenic acid, it is obvious that the arseniate of nickel, separated by the carbonates from its solution in acids, is a sub-salt, containing one and a half as much base as the neutral arseniates. The same takes place with the arseniates of cobalt, copper, and peroxide of iron obtained in the same way, but not with the ar. seniate of lime precipitated from its acid solutions by a great excess of ammonia.

Ten grammes of arseniate of nickel heated in a crucible lined 
with charcoal, as in iron assays, gave a well-melted button of arseniuret of nickel weighing $6.15 \mathrm{gr}$. It was grey without any tint of red, brittle, the fracture granulated, almost even, and somewhat approaching to lamellar; in its centre it contained a cavity lined with brilliant needles; it was not at all- magnetic. This compound contained nearly a half part less of arsenic than the native arseniuret of nickel, and consequently one atom of arsenic to two of nickel.

The Sulphate of Nickel ervstallizes in long oblique prisms with rhomboid bases, and changes intoliexaëdral prisms by a facet on each obtuse angle. These crystals are perfectly transparent, and of a beautiful emerald green. By exposure to"air and solar light they gradually effloresce, and become opake without losing their form. When calcined, this sulphate was composed of 0.478 per cent. of protoxide of nickel, and 0.522 of sulphuric acid. Ten grains of this sulphate reduced in a charcoal crucible at the heat of an iron assay, gave a well-melted button of sulphuret, which was grey with a shade of yellow, brittle, with a fracture lamellar in one direction, and granulated in the other, and strongly magnetical. It appears to consist of 1 atom of sulphur and 2 of nickel.

The Carbonate of Nickel obtained by precipitating a solution of thismetal with a subcarbonated alkali, is of a fine apple-green verging to yellow, and retains this colour after exposure to the sun. If it contains ever so little cobalt its tint is sensibly altered, and passes to a dirty greyish violet.

It is composed of

$$
\begin{aligned}
& \text { Protoxide of nickel ...... } 0.475 \\
& \text { Carbonic acid .......... } 0 \cdot 140 \\
& \text { Water .............. 0.385__ } 1.000
\end{aligned}
$$

This salt appears to contain $l$ atom of acid to $l$ atom of oxide.

When a saturated carbonate instead of a subcarbonate is employed, the precipitate is of a very pale green, and becomes light and pulverulent when dried in the sun.

It consists of

$$
\begin{aligned}
& \text { Protoxide of nickel ....... } 0 \cdot 483 \\
& \text { Carbonic acid ......... } 0.210 \\
& \text { Water .............. 0.307_ } 1.000
\end{aligned}
$$

It appears to contain 3 atoms of acid to 2 of base.

These carbonates of nickel are readily decomposed by heat. When they are calcined in a dull red heat with exposure to air, they produce a fine black peroxide of nickel, but in a stronger heat this changes to a pure olive-coloured protoxide. 